\title{
DESIGN OF A MICRO TOOL FOR HIGH-EFFICIENCY MICRO SLOTTING
}

\author{
L. Zhong ${ }^{1 *}$, D. Peng ${ }^{1}$, Q. Yin ${ }^{1}$ \\ ${ }^{1}$ China Academy of Engineering Physics, Institute of Machinery Manufacturing Technology, Mianyang, China \\ *Corresponding author; e-mail: zlidorothy@163.com
}

\begin{abstract}
Micro structure with arrayed slots have excellent performances, including friction, lubrication and diffraction, because of their arrayed features. Numerous fields are concentrating on this structure, attributed to its excellent properties. In this paper, the conventional micro end milling tool was analyzed, and the drawbacks in micro slot milling were discussed. A micro slotting tool with a novel structure was proposed, especially focused on fabricating micro arrayed slots with high efficiency. Large tool shank was utilized to avoid weak stiffness resulting from small shank of traditional micro tool, two-line ultra-hard blades with symmetrical distribution were designed to ensure simultaneous milling of multi-slots. Additionally, tool material selections and manufacturing scheme of the tool were suggested.
\end{abstract}

\section{Keywords:}

Tool design; Micro slotting tool; Novel structure; Micro arrayed slots; High efficiency

\section{INTRODUCTION}

Micro arrayed slots are typical micro features, their sizes range from several microns to several millimeters [Brinksmeier 2010], and have multiple capacities because of the arrayed structures, such as friction, lubrication and diffraction and so on [Bruzzone 2008] [Fang 2013] Numerous fields, including aerospace, biomedical, and optical engineering, are concentrating on this micro structure, attributed to it excellent properties. The quality of the arrayed slots, such as dimensional accuracy, burrs, and surface integrity, has dominant influence on the service performances. It is extremely important to ensure high accuracy and consistency of the micro slots, as well as the high surface integrity. Additionally, a variety of materials were employed to manufacture micro arrayed slots in practical applications [Zhong 2017]. Thus, there is an urgent demand to achieve high-quality machining of micro arrayed slots of various materials. Micro electrical discharge machining (EDM), micro laser beam machining and micro milling are common methods for the machining of micro slots [Maity 2012] [Bodziak 2014]. While the quality of the side walls of micro slots fabricated by micro EDM and laser beam machining, is poor and the aforementioned techniques also shows inefficiency [Arif 2012]. Micro milling in contrast with other micro machining methods are fewer material restrictions, better machined quality and higher efficiency [Chae 2006] [Dornfled 2006] [Fleischer 2008]. Those merits make it an excellent technique to manufacture micro arrayed slots. Tool technique is key factor in micro milling [Zhang 2013] [Aurich 2012] [UhImann 2005], the study of micro milling are concentrated on it, and tool design has focused on the optimal design of tool structure [Cheng 2009]. Fang et al. [Fang 2003] studied the D-type, $\triangle$-type and two-flute end-mills, and concluded that the D-type tools are suitable for micro milling. Cheng et al. [Cheng 2011] summarized the typical micro milling tools, and proposed a new design criterion. A micro ball-end mill with a new configuration was proposed by Liang et al. [Liang 2018], milling performance was improved because of the conical flank face. However, micro milling tools of conventional structure are prone to breakage because of their small scale, resulting in large burrs, poor dimensional accuracy and surface integrity, and thus, the high machining requirements of micro arrayed slots cannot be obtained. To enable effective and efficient micro milling of micro arrayed slots on different materials, the structure of the traditional micro milling tools were analyzed and the drawbacks were discussed, a micro slotting tool with a novel structure was proposed in this paper.

\section{CONVENTIONAL MICRO MILLING TOOL AND ITS DRAWBACKS}

One of the differences between micro milling and macro milling is the tool. The diameter of micro milling tool is extremely small and the stiffness is weak, and the corresponding forces which the micro milling tool can encounter are also small, thus the milling parameters, such as feed per tooth, cutting depth, is limited. The sketch of conventional micro milling tool is depicted in Figure 1. The tool tip endures cutting forces when machining, the tool resembles a cantilever beam. And tool stress $\sigma$ and the maximum deflection of the tool tip $w$ can be calculated by the following formulae:

$$
\begin{aligned}
& \sigma=\frac{32 F L}{\pi D^{3}}=\frac{32}{\pi} \times F \times \frac{L}{D} \times \frac{1}{D^{2}} \\
& w=\frac{64 F L^{3}}{3 \pi E D^{4}}=\frac{64}{3 \pi E} \times F \times\left(\frac{L}{D}\right)^{3} \times \frac{1}{D}
\end{aligned}
$$

when $F$ represents milling force, $L$ represents the length of cutting edge, $D$ represents the diameter of cutting edge, and $E$ represents elastic modulus. When the $F=5 N, L / D=1$, 
the relationship between the tool stress and the tool diameter is shown in Fig.1. It can be calculated that when $D=1 \mathrm{~mm}, \sigma=50 \mathrm{MPa}$, while $D=0.2 \mathrm{~mm}, \sigma=1270 \mathrm{Mpa}$. It can be observed that the stress increased sharply with the decrese in the diameter of micro tool $(D<1 \mathrm{~mm})$, thus the strength of the micro tool should be higher compared with the conventional tool.

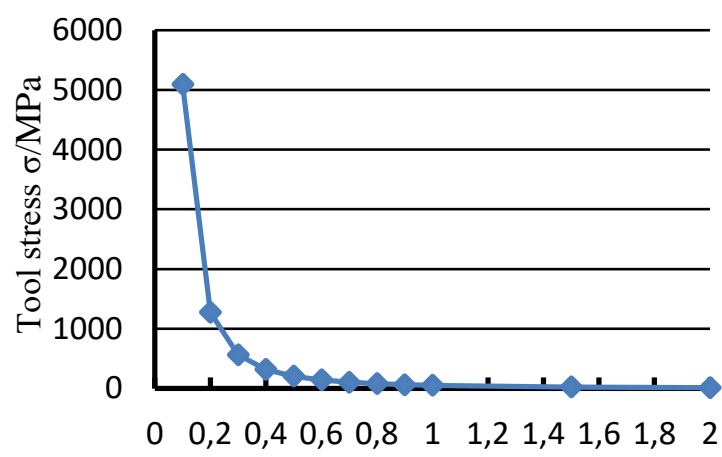

Tool diameter $\mathrm{D} / \mathrm{mm}$

Fig. 1: The tool stress changes with the tool diameter.

It can be observed in formulae (1) and (2) that, when the ratio of the length of cutting edge to the tool diameter $(\mathrm{L} / \mathrm{D})$ is constant, the maximum stress and the deflection of the tool tip is inversely proportional to the tool diameter's power and the tool diameter, respectively. When the $L / D$ is constant, the stress of micro tool shows exponential increasing as the diameter decreases. It has an unfavourable influence on the stability of the tool, resulting in instability of micro milling process. Once the stress is greater than the yield limitation of the tool material, the tool breakage even occurs. And the deflection of tool tip is increased with the decrease of the tool diameter. Since both the sizes of tool size and machining features are small in micro milling, the reflection on machining features caused by the slight deflection is large (see Fig. 2), the practical tool diameter $D_{2}$ is greater than ideal tool diameter $D_{1}$, resulting in the deterioration of precision and burr formation. The sketch of slot milling using conventional micro milling tool is showed in Figure 3 . The verticality of micro-groove side wall, planarity of groove bottom, and burr of micro-groove side will be seriously deteriorated, which cannot meet the requirements of high precision and high surface integrity of micro-groove structure, due to the existence of tool deflection.

With regard to the structure of micro arrayed grooves, high dimensional accuracy and surface integrity of the microgrooves should be ensured, and the consistency between multiple microgrooves is also strictly required. Even if the hardness of the milling of small shaping metal copper, aluminum, and so on, the conventional micro milling cutter is inevitable to produce wear, resulting in a decline in processing quality. If many sharp tools are used for array micro-groove machining, the replacement of the tool will introduce errors, which is not conducive to the realization of micro-groove precision machining.

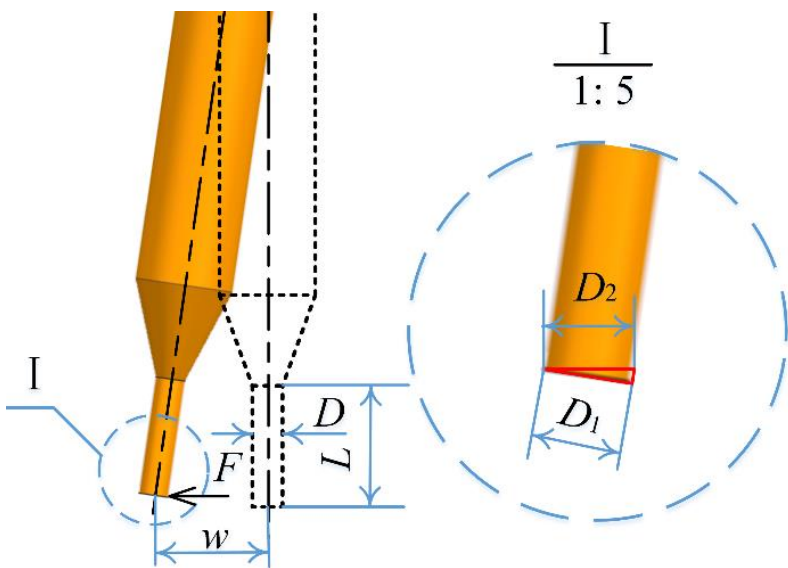

Fig. 2: The structure sketch of conventional micro milling tool.

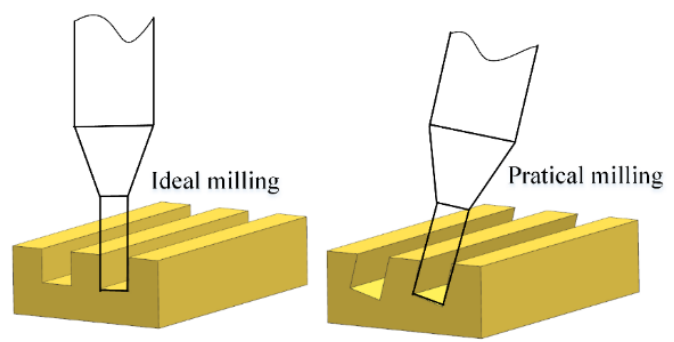

Fig. 3: The sketch of slot milling using conventional micro milling tool.

\section{THE DESIGN OF HIGH EFFICIENCY MICRO SLOTTING TOOL}

\subsection{Design of the tool structure}

Aimed at high-efficiency and high-quality machining of the arrayed micro-groove structure, a micro slotting tool with a novel structure was proposed in this paper. The design diagram is shown in figure 4 . The tool comprices a handle and two series of micro-blades symmetrically fixed on it along its axial direction. Characteristic dimension was deftly converted from diameter of conventional micro milling cutter into the width of the main cutting edge in the structure, avioding the problems of insufficient rigidity and fracture caused by the small diameter of micro milling cutter. The width of the main cutting edge is designed to be the range from $0.05 \mathrm{~mm}$ to $1 \mathrm{~mm}$, which corresponds to the width of the micro grooves. The diameter of the handle is designed to be $0.5 \mathrm{~mm}-1 \mathrm{~mm}$, which is comparable to the conventional tools. It can ensure the axial stiffness of the cutting tool. For conventional micro tools, high cutting speed requires high spindle speed because of the small diameter (generally 0.1 $\mathrm{mm}-1 \mathrm{~mm}$ ), in this case, the tools were prone to vibration, easily damaged, and the milling process would be unstable. While the micro arrayed slotting tool designed in this paper, the handle diameter was similar to marco tools. On the one hand, the mounting process of the blades and the handle was simplified, on the other hand, high milling speed could be obtained under low spindle speed, avoiding the problems caused by high spindle speed, the machining reliability and stability of the cutting tool could also be increased. In addition, multiple micro arrayed grooves, which is equal to the number of the blades, can be machined simultaneously (see Fig. 5). The machining efficiency was increased significantly and the wear of a single blade was decreased, the problems such as poor dimensional accuracy and consistency, and large burrs caused by conventional micro tool can be avioded MM Science Journal | 2019 | Special Issue on HSM2019 
consequently. Therefore, it is favorable to meet the machining requirements of high efficiency, consistency and surface integrity.

The structure diagram of the blades was depicted in figure 4 , the efficient length of the blade was from $0.1 \mathrm{~mm}$ to $1 \mathrm{~mm}$, the interval between two blades was from $0.05 \mathrm{~mm}$ to $1 \mathrm{~mm}$, and the number of the blades was from 3 to 300 . With regard to the structure of the cutting edge, the schematic diagram of the cutting edge was shown in Fig. 6. One main cutting edge and two minor edges were involved. The angle between the main flank face and the rake face was acute angle, the main rake angle, minor rake angle $I$, minor rake angle $\Pi$, minor flank angle $I$, minor flank angle $\Pi$ were all 0 degree. The main flank face was from 8 degrees to 15 degrees. The conventional micro tool just has end and side edges, it was unfavorable to side wall machining. The two minor edges of the proposed tool can ensure the high quality of the side wall of the micro slots.

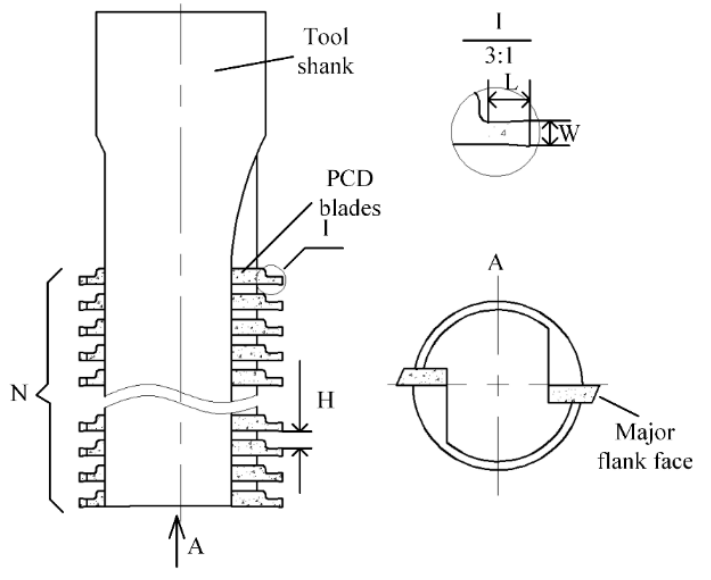

Fig. 4: The structure diagram of the blades.

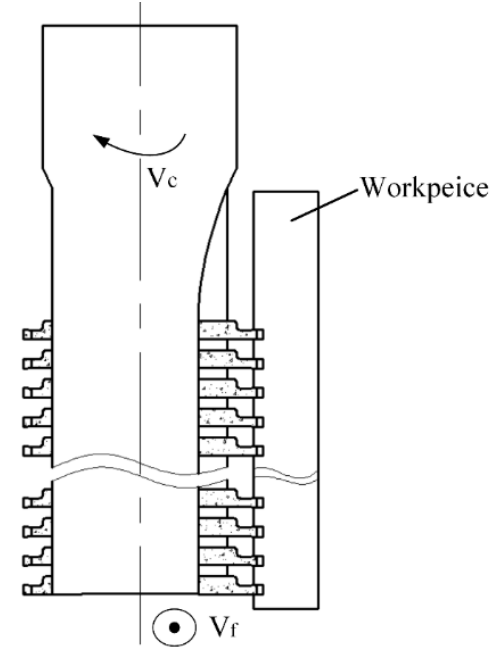

Fig. 5: The milling mode of the proposed tool.

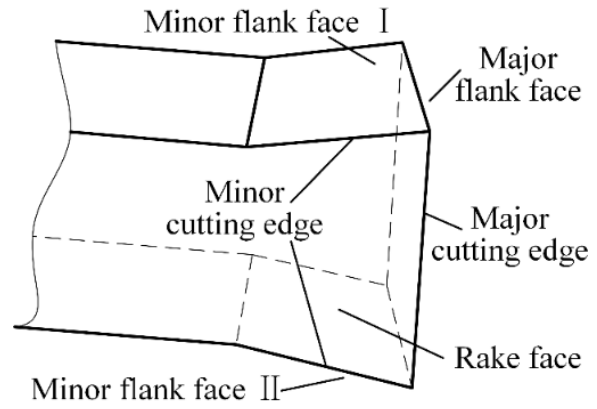

Fig. 6: The schematic diagram of the cutting edge.

\subsection{Selection of the tool materials}

Size effect is an unignorable phenomenon in micro milling, it has a significant effect on surface quality, burrs, cutting performance of the tools and tool life. And this phenomena is closely related to the ratio of undeformed chip thickness and cutting edge radius. When the undeformed chip thickness is constant, the smaller the cutting edge radius, the size effect phenomena is less dominant [Oliveira 2015] [Aramcharoen 2009]. Therefore, under the same cutting conditions, the sharp edge is conducive to minimize burr formation and improve the surface quality.

The polycrystalline diamond, single crystal diamond, cubic boron nitride, cemented carbide materials are common materials utilized to manufacture micro tools. Micro tools made of cemented carbide and their coating tools are common commercial tools, these tools could be sharp, the cutting edge radius could be several microns. However, affected by the material properties, cemented carbide particles, which participates in the cutting process, is very limited, and the strength of the blade depends on the strength of the bonded materials $\mathrm{Co}$, which is prone to peeling off. When the coating is added to the tool, the cutting edge radius increases, tool wear will be increased, and the sharpness of the tool cannot be maintained. In contrast, Ultra-hard materials, such as polycrystalline diamond, single crystal diamond, cubic boron nitride, have extremely high hardness, wear resistance, low friction coefficient, high bonding phase strength, they have great advantages in manufacturing sharp edge and maintaining sharpness, and tools made of them have remarkable potential to manufacture micro arrayed slots. Compared with other ultra-hard materials, polycrystalline diamond have excellent characteristics, such as isotropic dissociation and impact resistance, and have no dissociative side, small grain is impacted under large load. The bonding material (Co) in PCD has good electrical conductivity, it is easy to realize controllable processing using WEDM. The size of PCD particles ranges from one micron to dozens of micrometers, they can satisfy the different processing conditions. In addition, PCD composite is economical. Therefore, PCD is selected as the blade material in this paper.

The stiffness of the tool handle affects the tool deformation. If the tool stiffness is not enough, the stability of the micro tool is insufficient, it is prone to vibration, the possibility of wear and fracture is increased, and affects the tool stability and machining accuracy of the parts. In this paper, a more ingenious tool structure is designed to avoid problems such as insufficient rigidity and fracture of the tool handle, but the tool handle with high rigidity is still focused in this paper. Therefore, cemented carbide with high elastic modulus is selected as tool shank material to ensure its rigidity. 


\subsection{Proposals of tool manufacturing}

The accuracy of tool manufacturing directly affects the degree of achievement of its design concept. Since the precision consistency of micro blades directly affects the consistency of machining micro groove, the

Tool manufacturing method of simultaneous cutting of micro blades was proposed in this paper to ensure the consistency of micro blades, as shown in Fig. 7. Firstly, the PCD composite was cut into rectangular blades, and then the multiple blades were overlapped together, and then the EDM method was used to conduct a single cutting to obtain blades with high consistency. Finally, the blades and the handle are welded together by high frequency response welding.
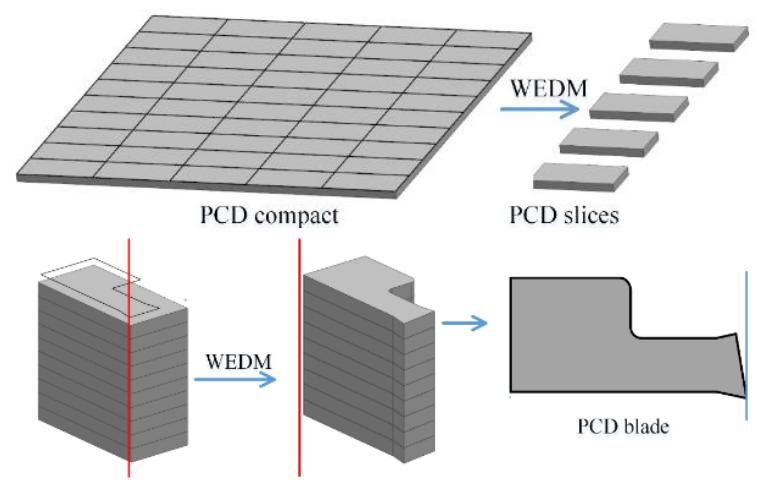

Fig. 7: The sketch of the blade manufacturing process.

\section{SUMMARY}

In this paper, aimmed at the micro milling difficulties of micro arrayed slots with high precision, high surface integrity, high consistency and high efficiency, research was conducted, the details are as follows:

(1) The conventional micro milling tools and its drawbacks in precision micro milling of micro arrayed slots were analyzed;

(2) Micro slotting tool with a new structure is proposed. The cutter innovatively adopted a larger size shank to avoid the problems of insufficient rigidity caused by the small size of conventional micro-milling cutter shank. With two rows of super-hard blades distributed symmetrically, multiple micro-grooves can be simultaneously manufactured in micro milling, and consequently, arrayed micro-groove structure with high quality and high efficiency could be achieved.

(3) The material selection of the new type of cutter and suggestions for high consistency manufacturing of the blades were put forward.

\section{REFERENCES}

[Brinksmeier 2010] Brinksmeier E., Riemer O., Glabe R., Lunemaim B., Kopylow C.V., Dankwart C and Meier A. Submicron functional surfaces generated by diamond machining. CIRP Annual-Manufacturing Technology, 2010,Vol.59, No.1, pp535-538, ISSN 0007-8506.

[Bruzzone 2008] Bruzzone A.A.Q., Costa H.L., Lonardo P.M., and Lucca D.A. Advances in engineered surfaces for functional performance. CIRP Annual-Manufacturing Technology, 2008, Vol.57, No.2, pp750-769, ISSN 00078506.

[Fang 2013] Fang F.Z, Zhang X.D., Weckenmann A., Zhang G.X., and Evans C. Manufacturing and measurement of freeform optics. CIRP AnnualManufacturing Technology, 2013, Vol.62, No.2, pp823-846, ISSN 0007-8506.

[Zhong 2017] Zhong L., Li L., Wu X., He N., Zhao G..L, and Yao C.J. Micro cutting of pure tungsten using selfdeveloped polycrystalline diamond slotting tools. International Journal of Advanced Manufacturing Technology, 2017, Vol.89, pp2435-2445, ISSN 0268-3768. [Maity 2012] Maity K.P., Singh R.K. An optimisation of micro-EDM operation for fabrication of micro-hole. International Journal of Advanced Manufacturing Technology, 2012, Vol.61, pp1221-1229, ISSN 0268-3768. [Bodziak 2014] Bodziak S., Souza A.F.D., Rodrigues A.R., Diniz A.E., Coelho R.T. Surface integrity of moulds for microcomponents manufactured by micromilling and electro-discharge machining. Journal of the Brazilian Society Mechanical Sciences and Engineering, 2014, Vol.36, No.3, pp623-635, ISSN 1678-5878.

[Arif 2012] Arif M., Rahman M., San W.Y. An experimental investigation into micro ball end-milling of silicon. Journal of Manufacturing Processes, 2012, Vol.14, pp52-61, ISSN 1526-6125

[Chae 2006] Chae J., Park S.S., Freiheit T. Investigation of micro-cutting operations. International Journal of Machine Tools and Manufacturing, 2006, Vol.46, pp313-332, ISSN 0890-6955.

[Dornfled 2006] Dornfled D., Min S., Takeuchi Y. Recent advances in mechanical micromachining. CIRP AnnualManufacturing Technology, 2006, Vol.55, pp745-768, ISSN 0007-8506

[Fleischer 2008] Fleischer J., Deuchert M., Ruhs C., Kuhlewein C., Halvadjiysky G., and Schmidt C. Design and manufacturing of micro milling tools. Microsystem Technologies, 2008, Vol.14, pp1771-1775, ISSN 09467076.

[Zhang 2013] Zhang Z., Peng H., and Yan J. Micro-cutting characteristics of EDM fabricated high-precision polycrystalline diamond tools. International Journal of Advanced Manufacturing Technology, 2013, Vol.65, pp99106, ISSN 0268-3768.

[Aurich 2012] Aurich J.C., Reichenbach I.G., Schuler G.M. Manufacture and application of ultra-small micro end mills. CIRP Annual-Manufacturing Technology, 2012, Vol.61, pp83-86, ISSN 0007-8506.

[Uhlmann 2005] Uhlmann E., Schaue K.r. Dynamic Load and Strain Analysis for the Optimization of Micro End Mills. Annals of the CIRP, 2005, Vol.54, No.1, pp75-78, ISSN 0007-8506

[Cheng 2009] Cheng X., Wang Z.G., Nakamoto K. and Yamazaki K. Design and development of a micro polycrystalline diamond ball end mill for micro/nano freeform machining of hard and brittle materials. Journal of Micromechanics and Microengineering, 2009, Vol.19, pp110, ISSN 0960-1317.

[Fang 2003] Fang F.Z., Wu H., Liu X.D., Liu Y.C., and Ng S.T. Tool geometry study in micromachining. Journal of Micromechanics and Microengineering, 2003, Vol.13, pp726-731, ISSN 0960-1317.

[Cheng 2011] Cheng X., Wang Z.G., Nakamoto K., and Yamazaki K. A study on the micro tooling for micro/nano milling. International Journal of Advanced Manufacturing Technology, 2011, Vol.53, pp523-533, ISSN 0268-3768.

[Liang 2018] Liang Z.Q., Li S.D., Zhou T.F., Gao P., Zhang D.D., and Wang X.B. Design and fabrication of a new micro ball-end mill with conical flank face. International Journal of MM Science Journal | 2019 | Special Issue on HSM2019 
Advanced Manufacturing Technology, 2018, Vol.97, pp3950, ISSN 0268-3768.

[Aramcharoen 2009] Aramcharoen A., Mativenga P.T. Size effect and tool geometry in micro milling of tool steel. Precision Engineering, 2009, Vol.33, No.4, pp402-407, ISSN 0141-6359.

[Oliveira 2015] Oliveira F.B.D., Rodrigues A.R., Coelho R.T., Souza A.F.D. Size effect and minimum chip thickness in micromilling. International Journal of Machine Tools and Manufacturing, 2015, Vol.89, pp39-54, ISSN 0890-6955. 